\title{
Evidence that a Nucleotide Sequence, "boxA," Is Involved in the Action of the NusA Protein
}

\author{
David I. Friedman and Eric R. Olson \\ Department of Microbiology and Immunology \\ The University of Michigan School of Medicine \\ Ann Arbor, Michigan 48109
}

\section{Summary}

We report the isolation of a mutation, boxA1, in the nutR region of the phage $\lambda$ genome. The nutR region, located downstream of the $p_{n}$ promoter, includes the site nutR where the $\lambda \mathbf{N}$ protein is thought to act to render subsequent transcription termination-resistant. We have previously suggested that the boxA soquence, 5'CGCTCTTA3' (or its RNA analog), 10cated 8 bp promoter-proximal to nuth, might be the recognition site for the E. coli host factor, NusA, which has been shown to be necessary for $\mathrm{N}$ action. The boxA1 mutation, an A:T to T:A transversion, results in a changed boxA sequence upstream of nutR, CGCTCTTT. This change is necessary for $\lambda$ to effectively use the NusA of Salmonella typhimurium, a NusA function not normally active with the $N$ product of $\lambda$. Other lambdoid phages with unique $N$ functions and nut sites that are normally active with the NusA of Salmonella have boxA sequences with the terminal three Ts. Moreover, sequences closely resembling boxA have been found near transcription termination sequences in $E$. coli operons where NusA has been shown to be involved in termination. These findings identify boxA as an important recognition signal for the NusA protein.

\section{Introduction}

The product of the nusA gene of $E$. coli has been implicated in both transcription termination and antitermination reactions. The gene was initially identified and mapped based on the isolation of a mutation, nusA1, which reduced the bacterium's ability to support the activity of the $N$ gene product of phage $\lambda$ (Friedman, 1971; Friedman and Baron, 1974). Subsequent studies have shown that NusA (or $L$ protein) plays a role in termination (Greenblatt et al., 1981; Kingston and Chamberlain, 1981; Farnham et al., 1982) and in stimulating $\beta$-galactosidase synthesis in a coupled transcription translation system (Kung et al., 1975).

Our studies have focused on the role of NusA protein in the action of the $N$ gene product. The $N$ protein regulates gene expression by permitting transcription to overcome many transcription termination signals (Roberts, 1969). A striking feature of the $\mathrm{N}$ reaction is its specificity; $\mathrm{N}$ protein primarily influences transcription from the early promoters $\mathrm{p}_{\mathrm{L}}$ and $\mathrm{p}_{\mathrm{R}}$ of $\lambda$ and the closely related phage 434 (Friedman et al., 1973; Adhya et al., 1974; Franklin, 1974; see Figure 1). Cis-acting mutations downstream of the p. promoter were isolated that failed to allow transcription initiating from $\mathrm{p}_{\mathrm{L}}$ to become termination-resistant. This led to the identifi- cation of a site, nutL, where $\mathrm{N}$ protein apparently is recognized (Salstrom and Szybalski, 1978). Sequence analysis showed that the nut mutations are located in a $17 \mathrm{bp}$ region of hyphenated dyad symmetry (Rosenberg et al., 1978). Analysis of sequences downstream of $p_{R}$ distal to the cro gene revealed a sequence nearly identical to nutL, homologous in 16 of $17 \mathrm{bp}$ (Rosenberg et al., 1978). Cloning experiments confirm that this site is contained in a region essential for $\mathrm{N}$ action (de Crombrugghe et al., 1979).

Much of the knowledge about $\mathrm{N}$ function has derived from studies with hybrid phages constructed by crossing $\lambda$ with other closely related phages; e.g., 434 (Kaiser and Jacob, 1957), 21 (Liedke-Kulke and Kaiser, 1967), and the Salmonella-phage P22 (Gemski et al., 1972; Botstein and Herskowitz, 1974). This family of phages, referred to as lambdoid, have nearly identically organized chromosomes but differ in the specificities of their analogous gene functions (reviewed by Friedman and Gottesman, 1983). Figure 1 shows the regions of nonhomology with $\lambda$ of some of these hybrids. Each hybrid phage contains primarily $\lambda$ DNA, but carries genes from the second phage for repressors, operators, and (except for 434 ) the $N$ gene, nut regions and some adjacent DNA (Westmoreland et al., 1969). Because these regions encode both repressors and cognate operators, and are thus responsible for repression when the phage is in the prophage state, these regions are collectively referred to as the immunity regions. The hybrid phages are named according to the immunity region they carry, and the specific hybrids are entitled $\lambda i m m 434, \lambda i m m 21$, and $\lambda i m m P 22$. In the case of the latter two phages, these $N$ gene products presumably only recognize their own nut sites. $\lambda i m m 434$, which shares the same $N$ gene as $\lambda$, has the same nut sites.

In addition to the $N$ protein, a number of bacterial factors, Nus ( $\mathrm{N}$-utilization substances), have been identified that appear to be needed for complete $\mathrm{N}$ action (Friedman et al., 1983). These factors, initially identified by mutations, have in some cases been biochemically characterized. The nus mutations, to a greater or lesser extent, result in the bacteria sharing a similar phenotype under restrictive conditions; $\mathrm{N}$-dependent $\lambda$ (e.g., wild type) will not grow in hosts with a nus mutation under restrictive conditions. However, $\lambda$ derivatives that are $\mathrm{N}$-independent, e.g., nin (Court and Sato, 1969), do grow in these hosts under the same conditions.

The best characterized nus gene is nusA (Friedman and Baron, 1974). The nusA gene encodes a $69 \mathrm{kd}$ protein (Greenblatt and $\mathrm{Li}, 1981$ ) that can act as a transcription termination factor. Our knowledge about the role of NusA in the action of $\mathrm{N}$ derives primarily from studies of $\mathrm{E}$. coli carrying a mutation in the nusA gene, nusA1 (Friedman, 1971; Friedman and Baron, 1974), and of hybrid bacteria carrying the nuSA gene from Salmonella typhimurium (Baron et al., 1970; Friedman and Baron, 1974). In bacteria with the nusA1 mutation or the Salmonella nusA gene, $N$ dependent $\lambda$ fail to grow, while $N$-independent derivatives 


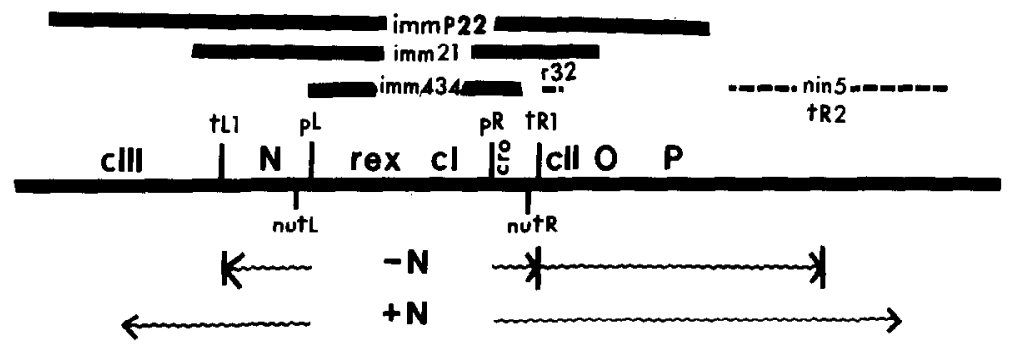

Figure 1. Genetic Arrangement and Gene Transcription in the "Early" Region of $\lambda$

The genetic arrangement in the early control region of $\lambda$ is shown in the middle. The three upper lines show the extent of the substitutions in the hybrid phages formed by recombination between $\lambda$ and the indicated phage. The lines under the map indicate the transcription patterns from the early promoters with and without $\mathrm{N}$ protein.

do grow. The growth patterns of hybrid phages differ in these bacteria. Although both the $N$ gene products of

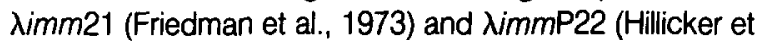
al., 1978) are less effective in nusA1 mutants, they are both active in hybrid bacteria with the nusA gene of Salmonella (Friedman and Baron, 1974).

We have identified a common sequence in the nut region located upstream of the $17 \mathrm{bp}$ region of dyad symmetry characteristic of all nut region sequences that were available for our examination (Olson et al., 1982). This sequence, CGCTCTTA, or slight variations of it, is found upstream of the nutR and nutL of $\lambda$, nutR of 21, and nut $L$ of P22. One of the variations observed was that this $8 \mathrm{bp}$ sequence in the 21 and $\mathrm{P} 22$ nut regions ends in three $T s$, nut $R_{21}$ having the sequence TGCTCTIT and nut $L_{22}$ having the sequence CGCTCTTT (see Olson et al., 1982). Although these phages have different $N$ products, they all require NusA for maximal $\mathrm{N}$ activity. This led to the suggestion that the sequence CGCTCTTA might be a recognition site for NusA. Examination of bacterial sequences in regions where NusA is postulated to work revealed closely related sequences. In particular, the CGC and $\mathrm{TT}$ are usually conserved. Based on this information, the sequence was named boxA (Olson et al., 1982).

Affinity chromatography was used to demonstrate a direct interaction between NusA and N proteins (Greenblatt and $\mathrm{Li}, 1981$ ). Moreover, a mutation in the $N$ gene permits the phage to overcome the nusA1 block (Friedman et al., 1981). Thus one probable reason why $\lambda$ fails to grow in the hybrid $E$. coli strain with the nus $A$ gene from Salmonella is that its $\mathrm{N}$ product cannot interact with the NusA protein from Salmonella. According to this explanation, $\lambda i m m P 22$ and $\lambda i m m 21$, both of which can grow in the hybrid bacterium, should synthesize $N$ products that can interact with NusA-Salmonella. These phages also share a similarity in the boxA sequence that differs from the boxA sequence found in $\lambda$. This difference might also be invoked to explain why $\lambda$ fails to grow, but P22 and 21 grow in hosts with the Salmonella NusA.

If the three Ts play a role in the recognition of the NusASalmonella by the boxA sequence, then it is plausible to assume that a $\lambda$ mutant that could utilize the NusA of Salmonella would have, in addition to an altered $N$, three Ts at the end of the box $A$ sequence in the nutR region. This assumes a tripartite interaction, N-NusA-BoxA.

We report the isolation and characterization of a mutant of $\lambda$ that grows well in a hybrid $E$. coli containing the nus $A$ gene from Salmonella typhimurium. As predicted, this phage has two types of mutations: one that maps in the region of the $N$ gene and a second in the nut $R$-associated boxA sequence. The latter results in an $A: T$ to $T: A$ transversion, yielding a run of three Ts identical to the sequence found in the boxAs of 21 and P22.

\section{Results}

\section{Isolation of Mutations Permitting $\lambda$ Growth with NusA Salmonella}

The strategy underlying the selection of a boxA mutation that would permit growth of $\lambda$ in an $E$. coli-Salmonella hybrid that has the nusA gene of Salmonella was based on the following assumptions. One, the Salmonella NusA requires the $\frac{T}{C}$ GCTCTTT sequence for optimal activity. Two, normal $\lambda N$ protein interacts poorly with the Salmonella NusA. Three, only the boxA sequence in the nutR region would have to be altered to permit $\lambda$ growth, because functions downstream of $t_{L 1}$ are not essential for lytic phage growth (Manly et al., 1969). Four, the most common class of mutants of $\lambda$ that will grow in the hybrid bacterium will be those that are $\mathrm{N}$-independent; these would likely have acquired a nin deletion (Court and Sato, 1969).

In order to facilitate the search, we initiated the selection for box $A$ mutations with a $\lambda$ derivative having two genetic changes from wild type. First, the phage has the punA mutation (Friedman et al., 1981) that maps in the $N$ gene. As punA allows $\lambda$ to grow in hosts carrying either the nUSA1 or nusE71 mutation, we assumed that the punA change would facilitate, at least partially, the interaction between $\mathrm{N}$ and the Salmonella NusA product. Second, the phage has the $r 32$ insertion (Brachet et al., 1970). This insertion sequence (IS2) is known to have a strong Rhodependent termination signal (de Crombrugghe et al., 1973). A nin deletion, which must be promoter distal to the $r 32$ insertion, would then not be expected to relieve the need for an active NusA product. This follows from the fact that $N$ activity at nut $R$ would be necessary to overcome the termination signal in the IS2 (Tomich and Friedman, 1977).

$\lambda$ punA 32 was mutagenized by growth in the mutD-5 mutator strain (Fowler et al., 1974). An aliquot of this lysate was placed on the bacterial lawn K1102, an E. coli strain with the nusA gene from Salmonella typhimurium. The 
plates were incubated overnight at $37^{\circ} \mathrm{C}$, and a few extremely small plaques were found at a frequency of $\sim 10^{-7}$. One of the plaques was purified and used to grow a lysate. The mutation responsible for growth on $\mathrm{K} 1102$ was mapped according to the cross shown in Figure 2. The results of the mapping studies indicate that this mutation is to the left of the immunity region. The fact that 36 of 37 of the phages that crossed out the $N$ amber mutations and did not have the $r 32$ insertion could partially grow in the hybrid bacterium $\mathrm{K} 1102$ located the responsible mutation near or within the $N$ gene. The mutation was preliminarily named pun $A^{\star}$. The isolation of $\lambda$ pun $A^{*}$ was consistent with the considerations enumerated previously. Further study of the mutant showed that it failed to form plaques on $\mathrm{K} 1102$ at $42^{\circ} \mathrm{C}$.

The poor growth of $\lambda$ punA ${ }^{*} 32$ on $\mathrm{K} 1102$ was assumed to reflect the fact that the altered $N$ was not sufficient and that a change giving a more effective NusA-boxA interaction was also necessary to permit effective growth of $\lambda$ on K1102. Therefore, $\lambda$ punA* was subjected to a second round of mutagenesis by growth in the mutD-5 strain. Mutant phages were isolated that could form plaques on a lawn of $\mathrm{K} 1102$ at $42^{\circ} \mathrm{C}$. Mapping studies identical to those used previously (see Figure 2) demonstrated that the mutation responsible for the improved growth on K1102 was located within or to the right of the $\mathrm{cl}$ gene. This mutation was preliminarily named $32^{\star}$. All of the 76 recombinants that had crossed out both the $B 2$ and the $N$ amber mutations failed to grow in $\mathrm{K} 1102$ at $42^{\circ} \mathrm{C}$. This is consistent with the change being in boxA.

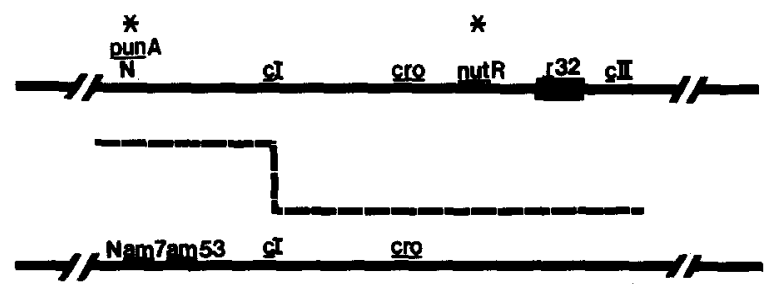

Figure 2. Genetic Cross Mapping Mutations Permitting Growth of $\lambda$ in K1102

The r32 derivatives with the * mutations that permit good growth in K1102 (the hybrid $\mathrm{E}$. coli with the nusA gene of Salmonella) were crossed with a $\lambda$ derivative carrying two amber mutations in the $N$ gene, Nam7,53. The host bacterium in this cross was the Sull containing strain, 6600 . A multiplicity of infection for each phage of 5 phages per bacterium was used. The infected bacteria were pelleted and resuspended in phosphate buffer at one tenth volume. They were then exposed to an ultraviolet irradiation dose of $300 \mathrm{ergs} / \mathrm{mm}^{2}$ for $60 \mathrm{sec}$. Following irradiation, the bacteria were resuspended in LB broth and allowed to burst by incubating at $37^{\circ} \mathrm{C}$. The phages produced by this joint infection were plated on a bacterial lawn of the $\mathrm{Su}^{\circ}$ host $\mathrm{K} 37$ at $32^{\circ} \mathrm{C}$. Because the 32 -containing parent forms a clear plaque as a result of the $\mathrm{B} 32$ insertion (Brachet et al., 1970), recombinants that have crossed out the 32 can now form turbid plaques while those that have crossed out the Nam mutations can grow in the Su host, $\mathrm{K} 37$

When the phage obtained in the initial selection, $\lambda$ punA* 32 , was crossed with $\lambda c / 857 \mathrm{Nam7,53} 36$ of 37 recombinants that formed turbid plaques carried the punA* mutation. When the phage obtained in the second step, $\lambda$ punA ${ }^{*} 32^{*}$, was similarly crossed, 76 of 76 turbid-plaque formers did not exhibit the ability to form good plaques on $\mathrm{K} 1102$. the phenotype of the $\lambda$ punA * $32 *$ parent.

\section{Identification of boxA Mutation}

The nut $R$ regions from the phages resulting from both the first and second rounds of the selection procedure were cloned into the $M 13$ derivative mp9 (see Experimental Procedures). The single stranded DNAs from each of the resulting M13 clones were used as templates in dideoxy sequencing reactions (Sanger et al., 1977). The results of the sequencing studies are shown in Figure 3. The mutant resulting from the first selection has a wild-type boxA sequence. On the other hand, the mutant resulting from the second selection has an A:T to T:A transversion at the $3^{\prime}$ end of boxA and now has a boxA sequence, 5'CGCTCTTT3'. Thus it has the three Ts positioned as in the boxA sequences of phages 21 and P22. The prediction of this precise change was based on the assumption that the three Ts are important in the recognition of the Salmonella NusA.

In reading the punA* $32^{*}$ sequence from the $\mathrm{Bgl}$ II site in cro to the 32 junction, no other deviations from the wildtype sequence (Rosenberg et al., 1978) were seen. Because the recombination experiments discussed in the next section demonstrate that the mutation responsible for good plating on $\mathrm{K} 1102$ maps between the $\mathrm{Bgl}$ II site in cro and the left-hand 132 junction, we conclude that the trans-

\section{Sequence of nut Region Showing box A Mutation}

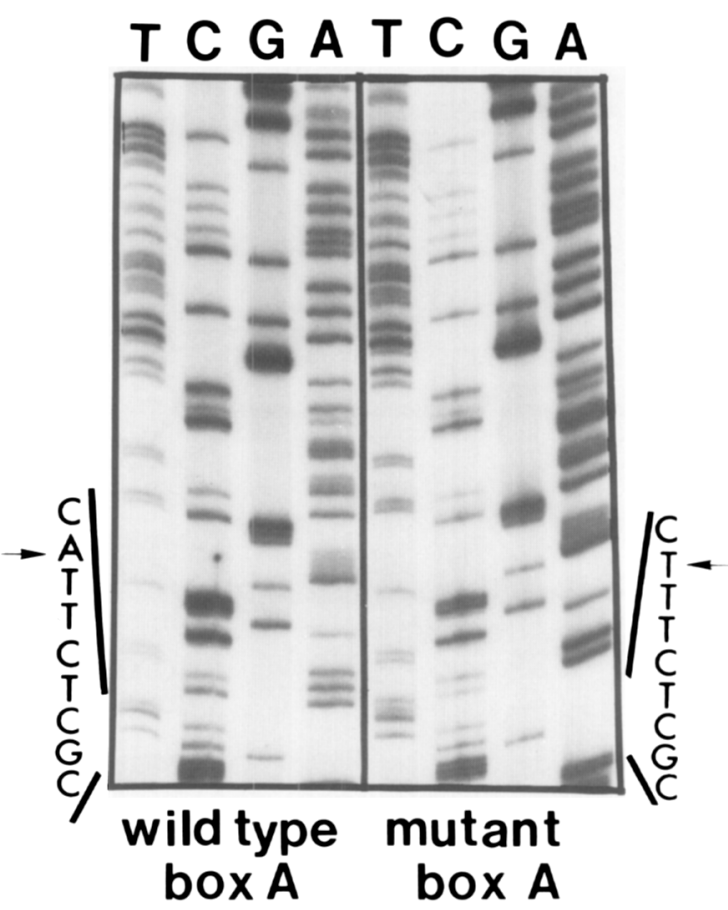

Figure 3. DNA Sequence of boxA1

The gel shows the sequences from the $3^{\prime}$ end of cro to the $B 2$ junction. The left-hand sequence is from $\lambda$ pun $A^{\star} B 32$ and the right-hand sequence is from $\lambda$ pun $A^{*} B 2^{*}$. The boxA sequences are listed on the side. The boxA1 mutation is the AT-TA transversion indicated by the arrows. 
version substituting the $T$ for the $A$ is responsible for this phenotype. The boxA mutation will now be referred to as boxA1.

\section{Rescue of boxA1 from a Cloned Fragment}

We next confirmed biologically that the mutation identified in the cloned fragment is responsible for the added effectiveness of phage growth in the hybrid bacterium. The mutant isolated in the first selection, $\lambda \rho u n A{ }^{\star} \beta 32$, was crossed with an $\mathrm{mp} 9$ derivative carnying the cloned fragment with boxA1. As a control we crossed $\lambda$ punA* 32 with a wild-type boxA sequence similarily cloned into mp9. Figure $4 A$ shows the details of the cross and lists the results. In the case of the cloned boxA1 sequence, recombinants were readily obtained; $4.8 \times 10^{-4}$ of the resulting phage plated well on $\mathrm{K} 1102$ at $42^{\circ} \mathrm{C}$. However, in the cross with the cloned wild-type boxA sequence, no recombinants $\left(<10^{-9}\right)$ were found.

In a second set of crosses a $\lambda$ derivative with the punA * mutation but lacking the $B 2$ was used. As shown in Figure $4 \mathrm{~B}$, the amount of homology between $\lambda p u n A^{*}$ and the $\mathrm{mp} 9$ derivative is nearly $80 \%$ less than that available in the cross using $\lambda$ punA* 32 . Moreover, the elimination of the 132 element means that mutations permitting growth on the hybrid bacterium should be isolated at a substantially higher frequency. The cross with the cloned boxA1 yielded a lower number $\left(\sim 10^{-6}\right)$ of recombinants that grew at $42^{\circ} \mathrm{C}$ in the hybrid bacterium, a result expected from the reduction in homology. The cross with the cloned boxA wild-type sequence yielded phages that grew in the hybrid bacterium, but at 10 times lower frequency. We attribute these phages to mutations in the $P-Q$ region that eliminate the effect of $t_{\mathrm{A2}}$ and thus render the phages $\mathrm{N}$-independent.

Because the second cross with boxA1 yields a significant number of recombinants above background that have acquired the ability to grow in the hybrid at high temperature, we conclude that the responsible mutation is between the $\mathrm{Bgl} \mathrm{II}$ site in $\mathrm{cro}$ and the $\mathrm{B2}$ junction. Since the sequence analysis of the cloned $\lambda$ material revealed only the one change from wild type, we further conclude that the $A$ to $T$ mutation is solely responsible for the added efficiency of growth in the hybrid bacterium.

An additional study suggests that the three Ts of the boxA1 mutant are necessary (if not sufficient) for growth

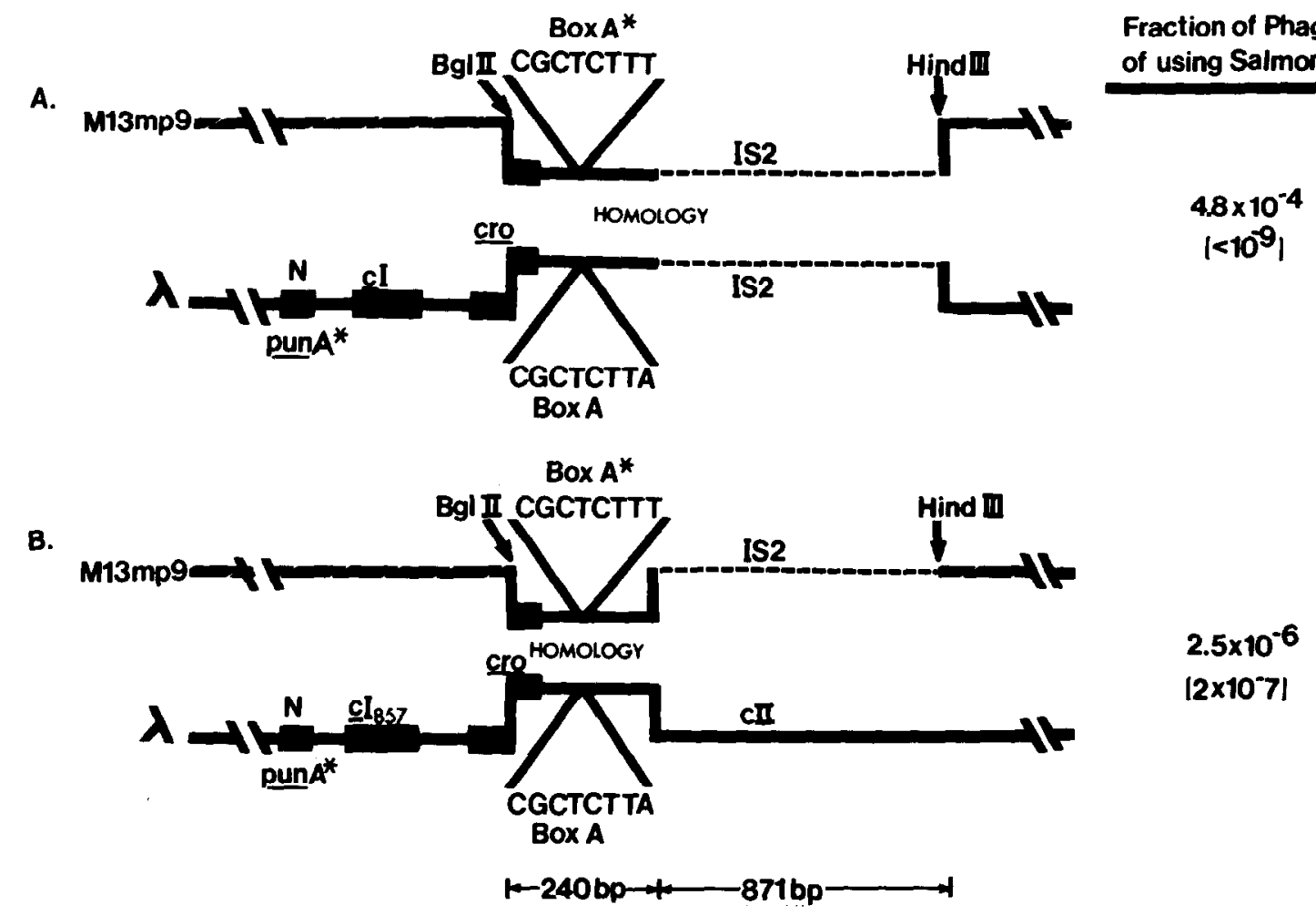

Figure 4. Schematic Representation of Crosses between $\lambda \rho u n A^{*}$ Derivatives and the nutR Region of boxA1 Cloned in M13mp9

In (A) the punA* phage carries the $B 2$ insertion. In (B), the phage does not carry the insertion.

Bacteria with the $\mathrm{M} 13 \mathrm{mp} 9$ clones were grown to $\sim 10^{8} / \mathrm{ml}$, infected with the appropriate phage at a multiplicity of 5 phages to 1 bacterium. Following a 15 min adsorption, bacteria were diluted into $L B$ broth and grown at $37^{\circ} \mathrm{C}$ for $90 \mathrm{~min}$. The cultures were then treated with chloroform to complete lysis. Lysates were plated for total phage titer using a bacterial lawn of K37 (contains the nuSA of E. coli) and for boxA1 recombinants on K1102 (contains the nuSA of Salmonella). Plates were incubated at $42^{\circ} \mathrm{C}$.

The fraction of phages capable of using NusA-Salmonella was calculated by dividing the titer obtained on K1102 by that obtained on K37. The numbers in parenthesis are the results of similar experiments using an $M 13 \mathrm{mp} 9$ derivative with the cloned boxA region from the $\lambda$ punA $r 32$ phage. That cloned fragment carries the wild-type boxA sequence. 
of $\lambda$ in $\mathrm{K} 1102$. A second independently, but identically, selected $\lambda \rho u n A^{*} B 2^{*}$ mutant was obtained starting with a different lysate of $\lambda$ pun $A^{\star} r 32$. The second mutation also mapped within or to the right of the $\mathrm{cl}$ gene. The nutR region from this mutant was cloned and sequenced using the same procedures used in analyzing the boxA1 mutation. This second mutation, boxA2, also has the $A$ to $T$ transversion resulting in the run of three Ts.

\section{Discussion}

Although a variety of studies led us to identify box $A$ as a possible NusA recognition sequence, this conclusion was an inference based on circumstantial evidence. Moreover, experiments using cloned nut $L$ sequences that do not include boxA suggest that this boxA sequence is dispensable for $\mathrm{N}$ action (Drahos et al., 1982). The isolation of the boxA1 mutation offers the first direct evidence that the boxA sequence is important for the NusA contribution to the $\mathrm{N}$ reaction. While not addressing the question of whether the interaction is with the DNA or RNA, the argument is based on the following considerations. One, the hybrid bacterium, $\mathrm{K} 1102$, has the nus $A$ region from Salmonella typhimurium. As P1 transduction was used to effect this substitution, not more than 2 min of the chromosome of the hybrid bacterium can be derived from Salmonella (lkeda and Tomizawa, 1965). Because the only known $\mathrm{E}$. coli gene involved in $\mathrm{N}$ action in this region is nus $A$, we have concluded that the substituted nus $A$ gene must be responsible for the failure of the hybrid bacterium to support $\mathrm{N}$ action. Two, the fact that the NusA product of Salmonella can support the action of the $\mathrm{N}$ analogs of phages 21 and P22 correlates with a shared difference in boxA; three Ts at the $3^{\prime}$ end of boxA instead of two. Three, therefore the isolation of box $A 1$ demonstrates that the three Ts in boxA must facilitate the action of NusA of Salmonella.

We can conclude that, at a minimum, boxA is involved in $\mathrm{N}$ action. The fact that an alteration of boxA permits the foreign NusA to support $\lambda-\mathrm{N}$ action leads to a more substantial conclusion: namely, that boxA is directly involved in the action of NusA. However, alternative explanations for these observations are possible. For instance, NusA could control the synthesis or modification of a second host function. This hypothetical second function could interact at boxA; the NusA of Salmonella, according to this scenario, alters either the expression or modification of that product so that it now requires the three Ts for proper activity.

We are at a loss to explain the results of the Drahos experiments (Drahos et al., 1982) which appear to show that a functional nut sequence need not have boxA. Perhaps the nature of the plasmid constructions used in those experiments permits $N$ to act with little or no NusA participation. These constructions have only one terminator between the promoter and the gene whose product is measured and this terminator is placed adjacent to the nut region. In contrast, in order for $\lambda$ to be viable, polymerase modified at nutR must overcome distal termination signals $\left(t_{R 2}\right)$. The difference in the two sets of experiments might then be explained by a need for NusA participation only when a more complete modification, permitting polymerase to overcome termination signals at distal sites, is required.

Arguing in favor of the direct involvement of boxA in NusA action is the observation of Olson et al. (1982) that in each case where NusA has been shown to be active in vitro, a strategically placed boxA-like sequence can be identified. In the case of the leader region of the $r n B$ operon (Kingston and Chamberlin, 1982) the sequence TGCTCTITA is found (Brosius et al., 1981). In the case of the trp operon terminators, $t$ and $t^{\prime}$ (Wu et al., 1981), the sequences found are CGCAGTTA and TGCGCTTA, respectively (Wu et al., 1980). Considering this information in light of the boxA1 mutation, we feel it leads to a compelling argument that the sequence $5^{\prime} \frac{\mathrm{C}}{\mathrm{T}} \mathrm{GCTC} T(\mathrm{~T}) \mathrm{A} 3^{\prime}$ is important for NusA action. Other studies from this laboratory (Olson and Friedman, unpublished data) suggest that the interaction between NusA and boxA occurs at the RNA level.

The fact that a two step procedure was necessary in isolating the boxA1 mutation indicates that another change is necessary in order for $\lambda$ to utilize the NusA of Salmonella. Preliminary studies indicate that this change is in the $N$ gene (A. T. Schauer and D. I. Friedman, unpublished data). This is not surprising as it has been shown that NusA and $\mathrm{N}$ can physically associate (Greenblatt and $\mathrm{Li}, 1981$ ).

The study reported in this paper adds the necessary confirmatory evidence to our previously published identification of boxA. How $\mathrm{N}$ and the various Nus substances, in particular NusA, interact at nut to modify transcription is still not completely understood. For a discussion of possible models the reader is referred to the review of Friedman and Gottesman (1983).

\section{Experimental Procedures}

\section{Phage and Cell Growth}

Media and methods for cell and phage growth have been described (Miller and Friedman, 1980).

\section{Bacteria and Phagea}

The bacterial strains used, the genotype relevant to this study, and the sources are: $\mathrm{K} 37$, $\mathrm{Su}^{\circ}$, from M. Yarmolinsky; $\mathrm{C600}$, Sull, from M. Yarmolinsky; JM101, Hfr, from W. Dunnick; K1617, mutD-5, from E. Flamm; K1102, nusA Salmonella typhimurium, from L. S. Baron.

Phages: M13mp9 was obtained from BRL. ApunAB2 was constructed in this laboratory by crossing $\lambda$ punA with $\lambda C / 857 \mathrm{Nam} 7,5332$ and selecting amber ${ }^{+}$phages that formed a clear plaque (Brachet et al., 1970). $\lambda c / 857 \mathrm{Nam} 7,53$ was obtained from $M$. Goltesman. $\lambda$ punA was isolated in this laboratory. $\lambda c / 857 \mathrm{Nam7}, 53 / 32$ was obtained from $W$. Szybalski.

\section{Mutageneais and Phage Crosses}

Phage mutants were obtained following growth under standard conditions in the mutD-5 (Fowler et al., 1974) strain, K1617. The methods employed in phage crosses are listed in the legends to Figures 2 and 4. 


\section{Cloning and Sequencing}

Lambda DNA was prepared from $5 \mathrm{ml}$ lysates as described (Maniatis, 1982). M13mp9 RF DNA was prepared from JM101-infected cells by the method of Clewell and Helinski (1969).

All ligations were carried out at $16^{\circ} \mathrm{C}$ for $10-24 \mathrm{hr}$ in $10 \mathrm{mM}$ Tris- $\mathrm{HCl}$ (pH8), $5 \mathrm{mM} \mathrm{MgCl}, 1 \mathrm{mM}$ dithiothreitol, $0.1 \mathrm{mM}$ ATP and $1 \mathrm{U}$ T4 DNA ligase. Bacteria were made competent for transformation as described by Cohen et al. (1972). Putative M13mp9 clones were screened either by dideoxy sequencing or by isolating the RF from $1 \mathrm{ml}$ cultures (Birnboim and Doly, 1979) and analyzing their restriction patterns by agarose gel electrophoresis.

The nutR regions from $\lambda$ punA* 32 and $\lambda$ punA ${ }^{*} \times 32^{*}$ were cloned into $\mathrm{M} 13 \mathrm{mp} 9$ by digesting the lambda DNA with $\mathrm{Bgl}$ II and Hind III and ligating the fragments into Bam HI, Hind III digested vector DNA. JM101 was transfected and clones containing an 871 bp piece from the Bgl II site in cro to the Hind III site in 32 were identified and sequenced by the dideoxy method of Sanger et al. (1977).

\section{Acknowledgments}

The authors thank Lisa Mashni-Olson for help on the figures. Al Schaver, Naomi Franklin, Wes Dunnick, and Mike Mowatt are thanked for helpful discussion and critical reading of the manuscript. We thank Emma Williams for heip in preparing the manuscript. This work was supported by grants from the National Institutes of Health.

The costs of publication of this article were defrayed in part by the payment of page charges. This article must therefore be hereby marked "adventisement" in accordanice with 18 U.S.C. Section 1734 solely to indicate this fact

Received May 9, 1983

\section{Reterences}

Adhya. S., Gottesman. M., and de Crombrugghe, B. (1974). Release of polarity in Escherichia coli by gene $N$ of phage $\lambda$ : termination and antitermination of transcription. Proc. Nat. Acad. Sci. USA 71, 2534-2538.

Baron, L. S., Penido, E., Ryman, I. R., and Falkow, S. (1970). Behavior of coliphage lambda in hybrids between Escherichia coli and Salmonella. J. Bact. 102, 221-233.

Birnboim, H. C., and Doly, J. (1972). A rapid alkaline extraction procedure for screening recombinant plasmid DNA. Nucl. Acids Res. 7, 1513-1523.

Botstein, D., and Herskowitz. I. (1974). Properties of hybrids between Salmonella phage P22 and coliphage $\lambda$. Nature 251, 584-589.

Brachet, $P$., Eisen, $H_{\text {. }}$ and Rambach, A. (1970). Mutations of coliphage $\lambda$ affecting the expression of replicative functions $O$ and $P$. Mol. Gen. Genet. 108, 266-276.

Brosius, J., Dulls, T. J., Sleeter, D. D., and Noller, H. (1981). Gene organization and primary structure of a ribosomal operon from Escherichia coli. J. Mol. Biol. 148, 107-127.

Clewell, D., and Helinski, D. R. (1969). Supercoiled circular DNA-protein complex in Escherichia coli: purification and induced conversion to an open circular DNA form. Proc. Nat. Acad. Sci. USA 62, 1159-1166.

Cohen, S. N., Chang, A. C. Y., and Hsu, C. L. (1972). Nonchromosomal antibiotic resistance in bacteria: genetic transformation of Escherichia coli by $R$ factor DNA. Proc. Nat. Acad. Sci. USA 69, 2110-2114.

Court, D., and Sato, K. (1969). Studies of novel transducing variants of lambda: dispensability of genes $N$ and $Q$. Virology 39, 348-352.

de Crombrugghe, B., Mudryj, M., DiLauro, R., and Gottesman, M. (1979). Specificity of the bacteriophage lambda $N$ gene product $(p N)$ : nut sequences are necessary and sufficient for the antitermination by $\mathrm{p} N$. Cell $18,1145-1151$.

de Crombrugghe, B., Adhya, S., Gottesman, M., and Pastan, I. (1973). Effect of Rho on transcription of bacterial operons. Nature New Biology 241, 260-264.

Drahos, P., Galluppi, G. R., Caruthers, M., and Szybalski, W. (1982). Synthesis of the nutL DNA segments and analysis of antitermination and termination functions of coliphage $\lambda$. Gene $18,343-354$.
Farnham, P. J., Greenblatt, J., and Platt, T. (1982). Effects of nusA protein on transcription termination in the tryptophan operon of Escherichia coli. Cell 29, 945-951.

Fowler, R. G., Degnen, G. E., and Cox, E. C. (1974). Mutational specificity of a conditional Escherichia coli mutator, mutD5. Mol. Gen. Genet. 133, 179-191.

Franklin, N. C. (1974). Altered reading of genetic signals fused to the $N$ operon of bacteriophage $\lambda$ : genetic evidence for the modification of polymerase by the protein product of the $\mathrm{N}$ gene. J. Mol. Biol. 89, 33-48. Friedman, D. I., Schauer, A. T., Mashni, E. J., Olson, E. R., and Baumann, M. F. (1983). Escherichia coli factors involved in the action of the $\lambda$ gene $N$ antitermination function. In Microbiology 1983, D. Schlessinger, ed. (Amer. Soc. Micro.), pp. 39-42.

Friedman, D. I., and Gottesman, M. (1983). The lytic mode of $\lambda$ development. In Lambda II, Hendrix et al., eds. (Cold Spring Harbor, New York Cold Spring Harbor Laboratory), in press.

Friedman, D. I., Schauer, A. T., Baumann, M. R., Baron, L. S., and Adhya, S. L. (1981). Evidence that ribosomal protein S10 participates in the contro of transcription termination. Proc. Nat. Acad. Sci. USA 78, 1115-1119.

Friedman, D. I., and Baron, L. S. (1974). Genetic characterization of a bacterial locus involved in the activity of the $N$ function of phage $\lambda$. Virology $58,141-148$

Friedman, D. I., Wilgus, G. S., and Mural, R. J. (1973). Gene N regulator function of phage גimm21: evidence that a site of $\mathrm{N}$ action differs from a site of $\mathrm{N}$ recognition. J. Mol. Biol. 81, 505-516.

Friedman, D. (1971). A bacterial mutant affecting $\lambda$ development. In the Bacteriophage Lambda, A. D. Hershey, ed. (Cold Spring Harbor, New York: Cold Spring Harbor Laboratory), pp. 733-738.

Gernski, P., Jr., Baron, L. S., and Yamamoto, N. (1972). Formation of hybrids between coliphage $\lambda$ and Salmonella phage P22 with a Salmonella typhimurium hybrid sensitive to these phages. Proc. Nat. Acad. Sci. USA 69, 3110-3114.

Greenblatt, J., and Li, J. (1981). Interaction of the sigma factor and the nusA gene protein of $E$. coll with RNA polymerase in the initiationtermination cycle of transcription. Cell 24, 421-428.

Greenblatt, J., MCLimont, M., and Hanly, S. (1981). Termination of transcription by the nuSA gene protein of Escherichia coli. Nature 292, 215-220.

Hilliker, S., Gottesmann, M., and Adhya, S. (1978). The activity of Salmonella phage P22 gene 24 product in Escherichia coli. Virology 86, 37-47.

Ikeda, H., and Tomizawa, J. (1968). Prophage P1, an extrachromosomal replication unit. Cold Spring Harbor Symp. Quant. Biol. 33, 791-798.

Kaiser, A. D., and Jacob, F. (1957). Recombination between related temperate bacteriophages and the genetic control of immunity and prophage localization. Virology 4, 509-521.

Kingston, R. E., and Chamberlin, M. J. (1981). Pausing and attenuation of in vitro transcription in the $r n B$ operon of $E$. coli. Cell 27, 523-531.

Kung, H., Spears, C., and Weissbach, H. (1975). Purification and properties of a soluble factor required for the deoxyribonucleic acid-directed in vitro synthesis of $\beta$-galactosidase. J. Biol. Chem. 250, 1556-1562.

Liedke-Kulke, M., and Kaiser, A. D. (1967). Genetic control of prophage insertion specificity in bacteriophage $\lambda$ and 21. Virology 32, 465-474.

Maniatis, T., Fritsch, E. F., and Sambrook, J. (1982). Molecular cloning: a laboratory manual. (Cold Spring Harbor, New York: Cold Spring Harbor Laboratory), p. 371.

Manly, K., Signer, E. R., and Radding, C. M. (1969). Nonessential functions of bacteriophate $\lambda$. Virology 37, 177-188.

Miller, H. I., and Friedman, D. I. (1980). An E. coli gene product required for $\lambda$ site-specific recombination. Cell 20, 711-719.

Olson, E. R., Flamm, E. L., and Friedman, D. I. (1982). Analysis of nutR: a region of phage lambda required for antitermination of transcription. Cell $31,61-70$.

Roberts, J. W. (1969). Termination factor for RNA synthesis. Nature 224, 1168-1174.

Rosenberg, M., Court, D., Shimatake, H., Brady, C., and Wulff, D. L. (1978). The relationship between function and DNA sequence in an intercistronic regulatory region of phage $\lambda$. Nature $272,414-423$. 
Salstrom, J. S., and Szybalski, W. (1978). Coliphage גnutL: a unique class of mutants defective in the site of $N$ utilization for antitermination of leftward transcription. J. Mol. Biol. 124, 195-221.

Sanger, F., Nicklen, S., and Coulson, A. R. (1977). DNA sequencing with chain-terminating inhibitors. Proc. Nat. Acad. Sci. USA 74, 5463-5467.

Tomich, P. K., and Friedman, D. I. (1977). Isolation of mutations in insertion sequences that relieve IS induced polarity. In Insertion Elements: Plasmids and Episomes, S. Adhya, A. Bukhari, and J. Shaprio, eds. (Cold Spring Hartbor, New York: Cold Spring Harbor Laboratory), pp. 99-107.

Westmoreland, B. C., Szybalski, W., and Ris, H. (1969). Mapping of deletions and substitutions in heteroduplex DNA molecules of bacteriophage lambda by electron microscopy. Science 163, 1343-1348.

Wu, A. M., Chapman, A. B., Platt, T., Guarente, L. P., and Beckwith, J. (1980). Deletions of distal sequences affect termination of transcription at the end of the tryptophan operon in E. coli. Cell 19, 829-836.

Wu, A. M., Christie, G. E., and Platt, T. (1981). Tandem termination sites in the tryptophan operon of Escherichia coli. Proc. Nat. Acad. Sci. USA 78, 2913-2917. 